American Journal of Biochemistry and Biotechnology 6 (2): 77-83, 2010

ISSN 1553-3468

(C) 2010 Science Publications

\title{
Effect of Exercise Training on Adiponectin Receptor Expression and Insulin Resistance in Mice Fed a High Fat Diet
}

\author{
${ }^{1}$ Naglaa Fathy Alhusseini, ${ }^{2}$ Nasr Arafat Belacy, ${ }^{2}$ Enas Mohammed Kasem and ${ }^{2}$ Mona Maher Allam \\ ${ }^{1}$ Department of Medical Biochemistry, Faculty of Medicine, Benha University, Egypt \\ ${ }^{2}$ Department of Physiology, Faculty of Medicine, Benha University, Egypt
}

\begin{abstract}
Problem statement: Adiponectin is an adipocyte secreted hormones, exerts its effects via the specific receptors. AdipoR1 and adipoR2 and plays a pivotal role in lipid and glucose metabolism. Approach: We investigated the effect of increased physical activities on insulin resistance and if this effect is modulated through adiponectin receptor expression. Results: We also assessed the effect of High Fat Diet (HFD) on adipoRs expression. Mice were subjected to 16 weeks of HFD protocol then to 4,6 and 8 weeks of exercise training. Following the experimental protocol the fasting plasma glucose, insulin and index of Homeostasis Model Assessment of insulin Resistance (HOMA-R) were evaluated. The mRNA expression of adiponectin receptors genes were also analyzed using reverse transcription RT-PCR. The consumption of high fat diet by the mice for 16 weeks resulted in a significant increase in weight associated with insulin resistance and associated with significant decrease in adiponectin receptors R1 and R2 expression in both liver and skeletal muscle. Exercise training for 4 weeks resulted in a significant improvement in the insulin resistance state, significant increase in expression of AdipoR1 and AdipoR2 in both liver and skeletal muscles. On increasing duration of exercise training for 6 weeks and 8 weeks there was significant improvement in insulin resistance and significant increase in the expression of AdipoR1 in liver, AdipoR1 and AdipoR2 in muscle, whereas liver AdipoR2 expression was significantly decreased. Conclusion/Recommendations: we conclude that the exercise training improves insulin sensitivity and up-regulates mRNA expression of AdipoR1 in both skeletal muscle and liver in mice and AdiopR2 in muscle and this suggests that the insulin sensitizing effect of exercise training may be mediated even partially through increased adiponectin receptor expression and up regulation of adiponectin receptors reaches certain level and increasing the duration of exercise adds no more improvement to insulin sensitivity or adiponectin receptor expression.
\end{abstract}

Key words: Adiponectin-gene expression-insulin resistance-exercise training

\section{INTRODUCTION}

It's now widely accepted that obesity is associated with many metabolic disorders including insulin resistance and type 2 diabetes (Kahn et al., 2006). It is well established that adipose tissue is more than just a passive reservoir for excess energy. It's a highly active endocrine organ plays an active role in the regulation of whole body metabolism by secreting a range of bioactive peptides, termed adipokines, they include for example: Leptin, resistin, tumor necrosis factor $\alpha$ and vesfatin (Galic et al., 2010). Adiponectin, also known as adipocyte component-related protein (weight $30 \mathrm{kDa}$; ACRP30), adipoQ, adipose most abundant gene transcript 1(apM1) is an adipokine that specifically and abundantly expressed in the adipose tissue (Berg et al.,
2001; Combs et al., 2002). Adiponectin has now been added on the list as a new and a very exciting player in the field of obesity related insulin resistance as its production and concentration actually decrease in obesity (Tsao et al., 2002). The association between obesity and adiponectin deficiency represents a very important step in the understanding of obesity related insulin resistance (Haluzik et al., 2004). Recently, two types of adiponectin receptors have been cloned, adiponectin receptor1 (AdipoR1) which is mainly expressed in skeletal muscle and adiponectin receptor 2 (AdipoR2) which is mainly expressed in the liver. Finding that inhibition of adiponectin receptor expression results in suppression of glucose uptake suggesting that the proposed effect on the glucose homeostasis and insulin sensitivity might be regulated by the expression level of adiponectin receptors

Corresponding Author: Naglaa Fathy Alhusseini, Department of Medical Biochemistry, Faculty of Medicine, Benha University, Egypt 
(Yamauchi et al., 2007). Interestingly the insulin sensitizing effects of exercise have similar metabolic effects as adiponectin in that exercise also promotes glucose uptake into the muscle and increase fatty acid oxidation (Vu et al., 2007). Therefore, the aim of the present study was to determine the effect of increased physical activities on insulin resistance and if this effect is modulated through adiponectin receptors expression. In this study the effect of high fat diet on AdipoR expression was also assessed to determine whether exercise training affects the expression on AdipoR exclusively.

\section{MATERIALS AND METHODS}

Experimental animals and protocols: Ten week old male mice $(\mathrm{n}=80)$ weighing $20-25 \mathrm{gm}$. without any previous preparation and with free access to food and water, were housed under controlled temperature and lighting conditions of $20-24^{\circ} \mathrm{C}, 12 \mathrm{~h}$ light-darkness cycle. A regular diet containing $27 \%$ protein, $13 \%$ lipid and $60 \%$ carbohydrates of total caloric requirement was available until the start of experiment once the experimental protocol was initiated, the mice divided into control (CON group $n=8$ ) prepared as the wild type control for comparisons of mRNA expression. Sixty eight mice were provided by high fat diet (fat represents $60 \%$, CHO $21.4 \%$ and protein $18.6 \%$ of total caloric requirements (Akagiri et al., 2008) for 16 weeks, 36 mice from them were submitted for exercise (ET group) and subdivided into 3 subgroups according to the exercise durations, $\left(\mathrm{ET}_{1} \mathrm{n}=12\right.$, Exercise duration $=6$ weeks $),\left(\mathrm{ET}_{2} \mathrm{n}=12 \mathrm{Ex}\right.$. duration $=8$ weeks $)$ and $\left(\mathrm{ET}_{3} \mathrm{n}=12 \mathrm{Ex}\right.$. duration $=12$ weeks $)$. The remained 32 mice were continuously provided with high fat diet without exercise: High Fat Diet (HFD group $n=32$ ). Weight and food consumption of all mice were measured daily.

Following acclimatization to swimming in water tank and according to swimming protocol of Reynolds et al. (2000), mice in ET group were exercised at $15 \mathrm{~min}$ swim interval, the training time were slowly increased to $45 \mathrm{~min}$ day $^{-1}$ over 1 week period, 5 days week ${ }^{-1}$ for a total of 6,8 and 12 weeks. At the end of duration of each exercise group and after overnight fasting, the ET mice and a corresponding number of mice from HFD group were decapitated and biceps femoris muscle, liver were removed and immediately placed in Cryo tubes and stored in RNA Later solution (Qiagen-GmbH Hilden, Germany) at $10 \mu \mathrm{L}$ per $1 \mathrm{mg}$ of tissue at $-80^{\circ} \mathrm{C}$. About $2 \mathrm{~mL}$ blood sample was collected from the right ventricle, placed immediately in vaccutainer tubes containing EDTA for plasma separated which stored at $-20^{\circ} \mathrm{C}$.
Blood chemistry assay: Glucose concentration was assayed spectrophotometrically using commercially available kit (Quantichrom Glucose Assay Kit). Serum insulin was assayed using INS-EASIA Kit (BioSource Europe SA). The index of homeostasis model assessment of insulin resistance (HOMA-R) insulin $\left(\mu \mathrm{U} \mathrm{mL} L^{-1}\right) \times$ glucose $\left(\mathrm{mg} \mathrm{dL}^{-1}\right) / 405$ (Matthews et al., 1985) of each animal was calculated from fasting plasma glucose and insulin concentrations.

Gene expression analysis: Biopsies of liver and muscles were taken and immediately placed in Cryo tubes and stored in RNA later solution (Qiagen, $\mathrm{GmbH}$, Hilden, Germany) at $10 \mu \mathrm{L}$ per $1 \mathrm{mg}$ of tissue at $-80^{\circ} \mathrm{C}$ for further processing.

From each of the stored liver and muscles biopsies, $30 \mathrm{mg}$ of the tissue were cut and homogenized using rotor-stator homogenizer (Art-Miccra D-8 Germeny) for $20 \mathrm{sec}$. Total RNA was extracted using RNeasy mini kit (Qiagen, GmbH, Hilden, Germany) following the protocol. $50 \mu \mathrm{L}$ of the eluted RNA was collected and immediately placed in ice.

Concentration of RNA sample was measured Spectrophotometrically $=44 \mathrm{ug} \mathrm{mL}^{-1} \mathrm{X}$ A260 X dilution factor (Wilfinger et al., 1997). The ratio of the readings at 260 and $280 \mathrm{~nm}$ (A260/A280) provides an estimate of the purity of RNA. Pure RNA has an A260/A280 ratio of 1.9-2.3.

One step RT-PCR: In rapid cycler PCR (G- Storm Thermal cycler, England) $10 \mu \mathrm{L}$ from each sample of extracted RNA were used in RT-PCR for each adiponectin receptor 1 , adiponectin receptor 2 and $\beta$ actin genes using one step RT-PCR kit (Qiagen Gmbh, Hilden, Germany) according to the manufacturer's instruction. Amplification was performed using the following primer sets provided by (Operon, inc Huntsville, Alabama Germany).: Forward primer 5 CTT CTA CTG CTC CCC ACA GC.3 reverse primer 5 - ACA CCA CTC AAG CCA AGT CC-3 for 376 bp fragment of Adipo R1, forward primer 5 - TCA GAG CAG GAG TGT TCG TG -3 reverse primer5 GGC AGC TCC GGT GAT ATA GA-3 for $315 \mathrm{bp}$ fragment of Adipo R2 and forward primer 5 -TGT TAC CAA CTG GGA CGA CA- 3 reverse primer 5 - GGG GTG TTG AAG GTC TCA AA- 3 for $588 \mathrm{bp}$ fragment of B-actin. PCR conditions for amplification of AdipoR1, AdipoR2 and $\beta$ actin were $50^{\circ} \mathrm{C}$ for $45 \mathrm{~min}, 95^{\circ} \mathrm{C}$ for $15 \mathrm{~min}$ and 40 cycles at $95^{\circ} \mathrm{C}$ for 1 min, $55^{\circ} \mathrm{C}$ for $1 \mathrm{~min}$ and $72^{\circ} \mathrm{C}$ for $2 \mathrm{~min}$.

Analysis of the amplified products: The amplified DNA was analyzed by electrophoresis. About $10 \mu \mathrm{L}$ of each reaction mixture and 1000 base pair (bp) ladder 
(Molecular weight marker) was separated on 2\% agarose gel containing $0.3 \mathrm{ug} \mathrm{mL} \mathrm{L}^{-1}$ of ethidium bromide. The bands were visualized using UV Tran illuminator $(254 \mathrm{~nm})$ and photographed using a digital camera 8 mega pixel. The image was transferred to be analyzed by computer software (Alpha InnoTech Gel Documentation System).

Statistical analysis: Data were expressed as mean \pm SD individual variables were compared using the student " $\mathrm{t}$ " test and paired " $\mathrm{t}$ " test according to Armistag (1983) using computer with SPSS version 16 program. Statistical significance was accepted at p-value $<0.05$ or lower.

\section{RESULTS}

Body weight and blood chemistry parameters during experimental protocol are shown in Table 1. Consumption of high fat diet HFD by the mice for 16 weeks resulted in a significant increase $(p<0.001)$ in weight associated with insulin resistance manifested by a significant increase in plasma insulin levels $(p<0.05)$, plasma glucose level $(p<0.001)$ and more over insulin resistance as assessed by HOMA was found to show significant increase $(p<0.05)$ as shown in Table 1. On increasing the duration of consumption of HFD for 20, 22 and 24 weeks there was no significant increase in the body weight or insulin resistant state on comparing them with the consumption of HFD for 16 weeks. Increase consumption of HFD for 20, 22 and 24 weeks had non significant decrease in the expression of adiponectin receptors AdipoR1 and AdipoR2 in both liver and muscle Fig. 1a-e and Chart 1 on comparing them with the consumption of HFD for 16 weeks. Studying the effect of exercise training for $45 \mathrm{~min}_{\text {day }}{ }^{-1}$ for 4 weeks resulted in an improvement in the insulin resistance state on comparing them with the same aged group as there was significant $(\mathrm{p}<0.05)$ decrease in plasma insulin, plasma glucose and more over HOMA as shown in Table 1.

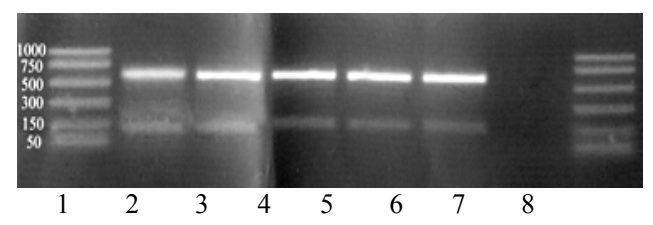

(a)

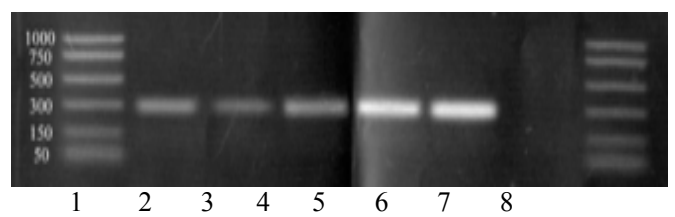

(c)

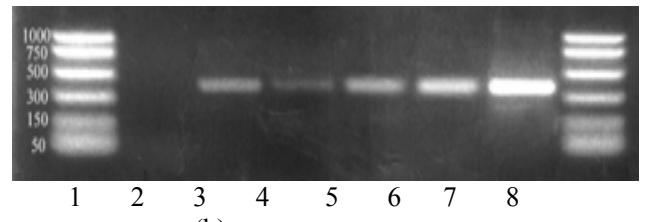

(b)

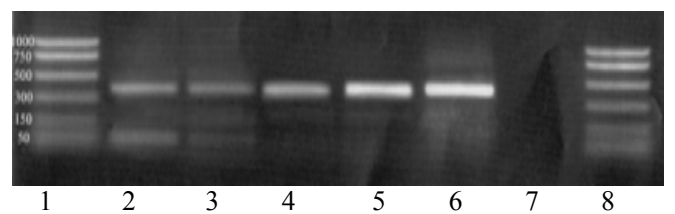

(d)

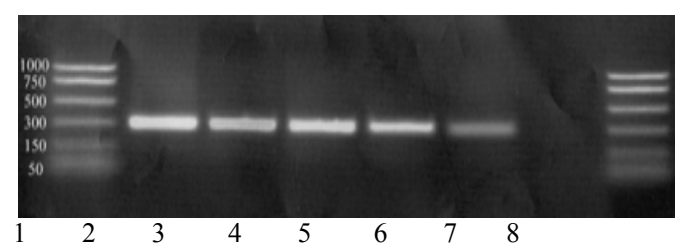

(e)

Fig. 1: Gel electrophoresis of the amplified products of target genes expressed; (a) B-actine mRNA expression as a house keeping gene in both liver and muscle tissues; Lane 1 and 8: 1000bp ladder, lane 2: CON, lane 3: HFD, lane 4: ET1, lane 5: ET2, lane6:ET3 and lane 7: negative control; (b) mRNA expression of AdipoR1 in muscle (376bp); Lane 1 and 8: 1000bp ladder, lane 2: negative control, lane 3:CON, lane 4:HFD, lane 5: ET1, lane6: ET2 and lane 7: ET3; (c) mRNA expression of AdipoR2 in muscle 315bp); Lane 1 and 8: 1000bp ladder, lane 2:CON, lane 3:HFD, lane 4:ET1, lane 5:ET2, lane6:ET3 and lane 7: negative control; (d) mRNA expression of AdipoR1 in liver (376bp). Lane 1 and 8: 1000bp ladder, lane 2: CON, lane 3: HFD, lane 4: ET1, lane 5: ET2, lane6:ET3 and lane 7: negative control; (e) mRNA expression of AdipoR2 in liver (315bp) Lane 1 and 8: 1000bp ladder, lane 2: CON, lane 3:HFD, lane 4: ET1, lane 5:ET2, lane6:ET3 and lane 7: negative control 
Am. J. Biochem. \& Biotech., 6 (2): 77-83, 2010

Table 1: Mean \pm SD of Body weight, Fasting plasma glucose and insulin among studied groups

\begin{tabular}{|c|c|c|c|c|c|c|c|c|}
\hline \multirow{2}{*}{$\begin{array}{l}\text { Groups } \\
\text { Parameters } \\
\text { Duration }\end{array}$} & \multirow{2}{*}{$\begin{array}{l}\text { CON } \\
\mathrm{N}=8 \\
16 \text { week } \\
\mathrm{N}=8\end{array}$} & \multicolumn{4}{|l|}{$\begin{array}{l}\text { HFD } \\
\mathrm{N}=32\end{array}$} & \multicolumn{3}{|l|}{$\begin{array}{l}\text { ET group } \\
\mathrm{N}=36\end{array}$} \\
\hline & & $\begin{array}{l}16 \text { week } \\
\mathrm{N}=8\end{array}$ & $\begin{array}{l}20 \text { week } \\
N=8\end{array}$ & $\begin{array}{l}22 \text { week } \\
\mathrm{N}=8\end{array}$ & $\begin{array}{l}24 \text { week } \\
\mathrm{N}=8\end{array}$ & $\begin{array}{l}\mathrm{ET} 1 \\
\mathrm{~N}=12\end{array}$ & $\begin{array}{l}\mathrm{ET} 2 \\
\mathrm{~N}=12\end{array}$ & $\begin{array}{l}\text { ET3 } \\
\mathrm{N}=12\end{array}$ \\
\hline Body weight & $32.1 \pm 2.5$ & $46.0 \pm 2.1^{*}$ & $46.9 \pm 1.9$ & $47.9 \pm 2.3$ & $48.3 \pm 2.1$ & $41.0 \pm 2.4$ & $39.4 \pm 1.8$ & $41.0 \pm 1.7$ \\
\hline FPG $\mathrm{mg} \mathrm{dL}^{-1}$ & $142.6 \pm 7.3$ & $204.0 \pm 25.1 *$ & $205.2 \pm 26.3$ & $208.3 \pm 27.5$ & $210.5 \pm 25.5$ & $149.0 \pm 31.3^{*}$ & $128.9 \pm 39.5$ & $123.3 \pm 30.4$ \\
\hline Insulin $\left(\mu \mathrm{U} \mathrm{mL}^{-1}\right)$ & $1.7 \pm 1.1$ & $4.3 \pm 2.9^{*}$ & $4.5 \pm 1.7$ & $5.4 \pm 1.9$ & $5.6 \pm 1.7$ & $0.9 \pm 0.3^{*}$ & $0.6 \pm 0.5$ & $0.7 \pm 0.1$ \\
\hline HOMA-R & $0.6 \pm 0.4$ & $2.04 \pm 1.2 *$ & $2.2 \pm 0.9$ & $2.4 \pm 0.8$ & $2.7 \pm 0.9$ & $0.3 \pm 0.1$ * & $0.2 \pm 0.2$ & $0.2 \pm 0.07$ \\
\hline
\end{tabular}

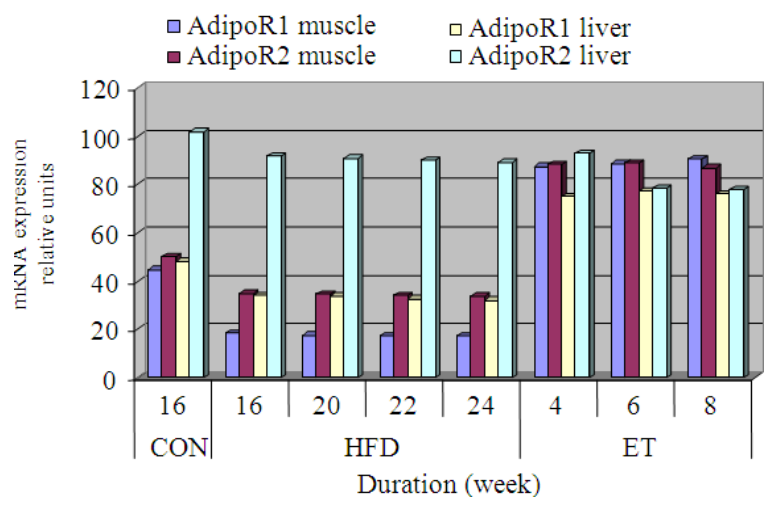

Cart 1: Relative expression of AdipoRs mRNA among studied groups

Also Exercise training for 4 weeks resulted in significant increase $(\mathrm{p}<0.001)$ in expression of adiponectin receptors AdipoR1 and AdipoR2 in both liver and skeletal muscles on comparing them with same aged group who received only HFD Fig. 1a-e and Chart 1. On increasing duration of exercise training for 6 weeks then for 8 weeks comparing them with the same aged group only received HFD for the same durations, there was significant improvement in insulin resistance regarding plasma insulin level as it showed significant decrease $(p<0.05)$, plasma glucose which significantly decreased $(\mathrm{p}<0.001)$ and moreover HOMA showed significant decrease $(\mathrm{p}<0.05)$ Also exercise training for 6 and for 8 weeks resulted in significant increase in the expression of adiponectin receptors AdipoR1 in liver, AdipoR1 and AdipoR2 in muscle, whereas liver AdipoR2 expression was significantly decreased $(\mathrm{p}<0.001)$.

\section{DISCUSSION}

Significant increase in mice weight and in insulin resistance go along with the fact that a HFDbased on hydrogenated vegetable oil- leads to insulin resistance and our findings are in agreement with (Akagiri et al., 2008) as they reported that high fat diet using hydrogenated vegetable oil as source of fat for 100 day produces insulin resistance in experimental animals assessed by weight gain, increased plasma glucose level and plasma insulin level and Barnea et al.,(2006) who stated that mice fed high fat diet for 4 months exhibited significantly greater weight gain, abnormal oral glucose tolerance test and elevated Homeostasis Model Assessment of insulin resistance (HOMA). Obesity induced insulin resistance could be explained by different mechanisms such as endocrinal mechanisms where the insulin sensitizing adipokines (e.g., adiponectin) decrease (Diez and Iglesias, 2003), while adipokines increasing insulin resistance increase (Hotamisligil, 2003; Ma et al., 2004; Qi et al., 2006). Another explanation was showed by (Lumeng et al., 2007) who reported that obesity induced insulin resistance via certain inflammatory mechanisms as obesity is characterized by macrophage accumulation in white adipose tissue and these macrophages are likely to contribute to a reduction in insulin sensitizing adipokines and an increase in other adipokines which decrease insulin sensitivity as discussed earlier. A third explanation was reported by (Houstis et al., 2006) who reported that obesity-related elevation of Fatty Acids (FAs) that cause oxidative stress which is considered a causative factor in the development of insulin resistance and the reversal of the imbalance between reactive oxygen species and antioxidants improves insulin resistance in mice and humans. Our finding support the assumption that reduced expression of adiponectin receptor plays a role in reduced insulin sensitivity caused by high fat diet (Naderali et al., 2003). Our findings were in agreement with (Huang et al., 2006) who reported that there is an impact of obesity on AdipoR1 in skeletal muscle as they exhibited lower expression levels in mice and (Barnea et al., 2006) who reported that there is a tissue specific effect of the high fat diet on the hepatic receptor expression as their expression was decreased in mice. These results are explained by (Inukai et al., 2004) who reported that 
there are some regulatory mechanisms of adiponectin receptors expression, one of them which have been reported is the plasma insulin levels and hyperglycemia. It has been shown that they repress receptors expression in both muscle and liver via activation of phosphatidyl inositol 3-kinase and inactivation of Foxo1.Interestingly (Tsuchida et al., 2004) has reported that the expression of AdipoR1/R2 in insulin target organs, such as skeletal muscle and liver, is significantly increased in fasted mice and decreased in re fed mice. Thus, the expression of AdipoR1/R2 appears to be inversely correlated with plasma insulin levels in vivo. Also the incubation of hepatocytes or myocytes with insulin reduced the expression of AdipoR1/R2 in vitro. These results highly suggest that the exercise is one of the main strategies in the reduction of insulin resistance, however there was no significant weight loss in the exercised group (Devlin and Horton, 2005).This improvement in insulin resistance in mice under the effect of exercise was reported by (Huang et al., 2006) and in humans by (Devlin and Horton, 1985; Dela et al., 1996; John et al., 2000). Also (Lee et al., 2005) reported that despite the absence of significant weight loss, moderate-intensity exercise was associated with significant reductions in abdominal fat and skeletal muscle lipid content in type II diabetes which was associated with improvement in insulin resistance state. And more over (Ross et al., 2000) showed that exercise training does not necessarily need to reduce body weight to have beneficial physiological effects on insulin resistance. Several Mechanisms have been proposed to account for these exercise-related improvements in insulin resistance state (Ivy et al., 1999) have proposed many pre receptor events e.g., increased muscle glucose delivery because of increased muscle capillary density and changes in muscle composition favoring increased glucose disposal as well as post receptor adaptations e.g., enhanced glucose transport via increased concentration of GLUT-4 in skeletal muscle (Dela et al., 1994), (Saengsirisuwan et al., 2002) and greater activity of the enzymes hexokinase II (Koval et al., 1998) and glycogen synthase (Ebeling et al., 1993). John Kirwan et al. (2000) reported that there is successfully identified up regulation of some post receptor steps such as IRS-1and PI3-kinase that leads to increase cellular glucose uptake in skeletal muscle. Lastly, the anti-inflammatory effects of exercise are well known and studies have shown that exercise reduces TNF- $\alpha$ concentrations, which may in part explain the increases in GLUT4 expression (Petersen and Pedersen, 2005). Our results mean that increased physical activity for 4 weeks is sufficient for inducing changes in adiponectin receptors expression and that the magnitude of these changes parallels the improvement in insulin resistance (Blüher et al., 2006; Zeng et al., 2007). Up-regulation of the adiponectin receptors could be explained by the reduction in blood insulin or glucose levels mediated by exercise training as the decrease in the expression levels of adiponectin receptors was reported to be directly related to increased plasma insulin levels and hyperglycemia (Tsuchida et al., 2004), however (Huang et al., 2006) showed that there was no significant changes observed in the expression of adiponectin receptors in mice were submitted for diet restriction for eight weeks despite the reduction in blood insulin and glucose levels, therefore exercise training might directly regulate the expression of adiponectin receptors, thereby being involved in improvements to the diabetic state and insulin sensitivity in mice. In contrast to these results, Punyadeera et al. (2005) showed that acute exercise training failed to change the expression levels of either AdipoR1 or AdipoR2 in the skeletal muscles of healthy volunteers they speculated that the divergent results from the effects obtained by chronic exercise arose from differences in exercise duration and intensity and sustained exercise of sufficient intensity might provide a way to increase AdipoR1 expression in skeletal muscle and thereby ameliorate reduced insulin sensitivity. Exercise training for 8 weeks resulted in significant decrease in the expression of AdipoR2 in liver. This decrease was explained by Kadowaki and Yamauchi (2005) as they reported that the increase in AdipoR1 expression in the liver in the exercised mice might compensate for the decreased expression of AdipoR2. Another explanation was proposed by Wang et al. (2004) and Staiger et al. (2004) as they reported that AdipoR1, but not AdipoR2, is involved in glucose or lipid metabolism. Also our findings are demonstrated that there are no additional significant improvements with increase exercise duration after 8 weeks. those were in agreement with Zhang et al. (2007), who reported that certain studies have not demonstrated additional benefits of increased exercise intensity or of training programs lasting significantly longer than the 12 weeks in humans on insulin resistance. 
Am. J. Biochem. \& Biotech., 6 (2): 77-83, 2010

\section{ACKNOWLEDGMENT}

Special thanks to staff members of Molecular Biology Unit, Benha Faculty of Medicine.

\section{REFERENCES}

Akagiri, S. Y. Naito, H.Ichikawa, K. Mizushima T. Takagi, et al., 2008. A Mouse Model of Metabolic Syndrome; Increase in Visceral Adipose Tissue Precedes the Development of Fatty Liver and Insulin Resistance in High-Fat Diet-Fed Male KK/Ta Mice. J Clin Biochem Nutr. 42: 150-157. DOI: $10.3164 /$ jcbn.2008022

Barnea,M., A. Shamay, Aliza H. Stark and Z. Madar, 2006. A high-fat diet has a tissue-specific effect on adiponectin and related enzyme expression. Obesity, 14: 2145-2153. DOI: 10.1038/oby.2006.251

Berg, A.H., T.P. Combs, X. Du, M. Brownlee and P.E. Scherer, 2001. The adipocyte-secreted protein Acrp30 enhances hepatic insulin action. Nat Med., 7: 947-953. DOI: 10.1038/90992

Blüher M, B. JW Jr,J. Lee, S. Kralisch , M. Fasshauer, N. Klöting, J. Niebauer, M. Schön , C. Williams , C. Mantzoros .2006. Circulating Adiponectin and Expression of Adiponectin Receptors in Human Skeletal Muscle: Associations with Metabolic Parameters and Insulin Resistance and Regulation by Physical Training. J. Clinical Endocrinol. Metabolism, 6: 2310-2316. DOI: 10.1210/jc.20052556

Combs, T.P., J.A. Wagner, J. Berger, T. Doebber and W.J. Wang et al., 2002. Induction of adipocyte complement-related protein of 30 kilodaltons by PPAR gamma agonists: A potential mechanism of insulin sensitization. Endocrinology, 143: 998-1007. PMID: 11861525

Dela, F., K.J. Mikines, J.J. Larsen and H. Galbo, 1996. Training-induced enhancement of insulin action in human skeletal muscle: The influence of aging. J. Gerontol., 51: 247-252. DOI: 10.1093/gerona/51A.4.B247

Devlin, J.T. and E.S. Horton, 1985. Effects of prior high-intensity exercise on glucose metabolism in normal and insulin-resistant men. Diabetes, 34: 973-979. DOI: 10.2337/diabetes.34.10.973

Diez, J.J. and P. Iglesias, 2003. The role of the novel adipocyte-derived hormone adiponectin in human disease. Eur. J. Endocrinol., 148: 293-300. DOI: 10.1530/eje. 0.1480293

Ebeling, P., R. Bourey, L. Koranyi, J.A. Tuominen and L.C. Groop et al., 1993. Mechanism of enhanced insulin sensitivity in athletes. J. Clin. Invest. 92: 1623-1631. DOI: 10.1172/JCI116747
Galic, S., J. Oakhill and G. Steinberg, 2010. Adipose tissue as an endocrine organ. Mol. Cell. Endocrinol., 316: 129-139. PMID: 19723556

Haluzik, M., J. Parizkova and M.M. Haluzik, 2004. Adiponectin and its role in the obesity-induced insulin resistance and related complications. Physiol Res., 53: 123-129. PMID: 15046547

Hotamisligil, G.S., 2003. Inflammatory pathways and insulin action. Int. Obes. Relat. Metab. Disord., 27: 53-55. PMID: 14704746

Houstis, N., E.D. Rosen and E.S. Lander, 2006. Reactive oxygen species have a causal role in multiple forms of insulin resistance. Nature, 440: 944-948. DOI :10.1038/nature04634

Huang, H. K. Iida, H. Sone, T. Yokoo, N. Yamada and R. Ajisaka .2006. The effect of exercise training on adiponectin receptor expression in KKAy obese/diabetic mice. J. Endocrinol., 189: 643-653. DOI: 10.1677/joe.1.06630

Inukai, K., Y. Nakashima, M. Watanabe, N. Takata and T. Sawa et al., 2004. Regulation of adiponectin receptor gene expression in diabetic mice. Am. J. Physiol. Endocrinol. Metab., 288: 876-882. PMID: 15613685

Ivy, J.L., T.W. Zderic and D.L. Fogt, 1999. Prevention and treatment on non-insulin-dependent diabetes mellitus Exerc. Sport Sci. Rev., 27: 1-35. PMID: 10791012

Kadowaki, T. and T. Yamauchi, 2005. Adiponectin and adiponectin receptors. Endocr. Rev., 26: 439-451. PMID: 15897298

Kahn, S.E., R.L. Hull and K.M. Utzschneider, 2006. Mechanisms linking obesity to insulin resistance and type 2 diabetes. Nature, 444: 840-846. DOI: $10.1038 /$ nature 05482

Kirwan J., L.del Aguila L, M. Hernandez, L. Williamson, J. O'Gorman, R. Lewis, and $\mathrm{K}$. Krishnan 2000. Regular Exercise Enhances Insulin Activation of Irs-1-Associated Pi3-Kinase in Human Skeletal Muscle. J. Appl. Physio. 88: 797-803. PMID: 10658053

Koval, J.A., R.A. DeFronzo, R.M. O’Doherty, R. Printz and H. Ardehali et al., 1998. Regulation of hexokinase II activity and expression in human muscle by moderate exercise. Am. J. Physiol. Endocrinol. Metab., 274: 304-308. PMID: 9486162

Lee, S., L. Kuk, E. Davidson, R. Hudson, K. Kilpatrick, E. Graham and R. Ross 2005. Exercise Without Weight Loss Is An Effective Strategy For Obesity Reduction In Obese Individuals With And Without Type 2 Diabetes. J Appl. Physiol. 99: 1220-1225. DOI: 10.1152/japplphysiol.00053.2005 
Lumeng, C.N., J.L. Bodzin and A.R. Saltiel, 2007. Obesity induces a phenotypic switch in adipose tissue macrophage polarization. J. Clin. Invest., 117: 175-184. DOI: 10.1172/JCI29881

Ma, L.J., S.L. Mao, K.L. Taylor, T. Kanjanabuch and Y. Guan et al., 2004. Prevention of obesity and insulin resistance in mice lacking plasminogen activator inhibitor 1. Diabetes, 53: 336-346. DOI: 10.2337/diabetes.53.2.336

Matthews, D.R., J.P. Hosker and A.S. Rudenski, 1985. Homeostasis model assessment: Insulin resistance and $\beta$-cell function from fasting plasma glucose and insulin concentrations in man. Diabetologia, 28: 412-419. PMID: 3899825

Naderali, E.K., D. Estadella and M. Rocha, 2003. A fat-enriched, glucose-enriched diet markedly attenuates adiponectin receptors mRNA levels in rat epididymal adipose tissue. Clin. Sci., 105: 403-408. PMID: 12780342

Petersen, A.M. and B.K. Pedersen, 2005. The antiinflammatory effect of exercise. J. Applied Physiol., 98: 1154-1162. DOI: 10.1152/japplphysiol.00164.2004

Punyadeera, C., A.H. Zorenc, R. Koopman, A.J. McAinch and E. Smit et al., 2005. The effects of exercise and adipose tissue lipolysis on plasma adiponectin concentration and adiponectin receptor expression in human skeletal muscle. Eur. J. Endocrinol., 152: 427-436. DOI: 10.1530/eje.1.01872

Qi, Y., Z. Nie, Y.S. Lee, N.S. Singhal and P.E. Scherer et al., 2006. Loss of resistin improves glucose homeostasis in leptin deficiency. Diabetes, 55: 3083-3090. DOI: 10.2337/db05-0615

Reynolds T., J.T. Brozinick, Jr., L.M. Larkin and Samuel W. Cushman1, 2000. Transient enhancement of GLUT-4 levels in rat epitrochlearis muscle after exercise training. J. Applied Physiol. 88: 2240-2245. PMID: 10846041

Ross, R., D. Dagnone, P.J. Jones, H. Smith and A. Paddags et al., 2000. Reduction in obesity and related comorbid conditions after diet-induced weight loss or exercise-induced weight loss in men. Random. Controlledtr. Ann. Int. Med., 133: 92-103. PMID: 10896648

Saengsirisuwan, V., F.R. Perez, T.R. Kinnick and E.J. Henriksen, 2002. Effects of exercise training and antioxidant R-(+)-lipoic acid on glucose transport in insulin-sensitive rat skeletal muscle. J. Applied Physiol, 92: 50-58. DOI: 10.1152/japplphysiol.000617.2001
Staiger, H., S. Kaltenbach, K. Staiger, N. Stefan and A. Fritsche et al., 2004. Expression of adiponectin receptor mRNA in human skeletal muscle cells is related to in vivo parameters of glucose and lipid metabolism. Diabetes, 53: 2195-2201. DOI: 10.2337/diabetes.53.9.2195

Tsao, T.S., H.F. Lodish and J. Fruebis, 2002. Acrp 30, a new hormone controlling fat and glucose metabolism. Eur. J. pharmacol., 440: 213-221. PMID: 12007537

Tsuchida, A., T. Yamauchi, Y. Ito, Y. Hada, T.Maki, S. Takekawa,J. Kamon, M. Kobayashi, R. Suzuki, K. Hara, N. Kubota, Y. Terauchi, P. Froguel, J. Nakae, M. Kasuga, D. Accili, K.Tobe, K. Ueki, R. Nagai and T. Kadowaki, 2004.Insulin/Foxo1 Pathway Regulates Expression Levels of Adiponectin Receptors and Adiponectin Sensitivity. J. Biol. Chem. 279: 30817-30822. DOI: 10.1074/jbc.M402367200

Vu.,V. M. Riddell, and G. Sweeney, 2007. Circulating adiponectin and adiponectin receptor expression in skeletal muscle: Effects of exercise. Diabetes/Metabolism Res. Rev., 23: 60-611. DOI: 10.1002/dmrr.778

Wang, H., H. Zhang, Y. Jia, Z. Zhang and R. Craig et al., 2004. Adiponectin receptor 1 gene as a candidate for type 2 diabetes an insulin resistance. Diabetes, 53: 2132-2136. DOI: 10.2337/diabetes.53.8.2132

Wilfinger, W.W., M. Mackey and Chomczynskip, 1997. Effect of $\mathrm{PH}$ and ionic strength on the spectrophotometric assessment of nucleic acid purity. Biotechniques, 22: 474. PMID: 9067025

Yamauchi, T., Y. Nio, T. Maki, M. Kobayashi and T. Takazawa et al., 2007. Targeted disruption of AdipoR1 and AdipoR2 causes abrogation of adiponectin binding and metabolic actions. Nat. Med., 13: 332-339. DOI: 10.1038/nm1557

Zeng, Q., L. Fu, K. Takekoshi, Y. Kawakami and K. Isobe, 2007. Effects of short-term exercise on adiponectin and adiponectin receptor levels in rats. J. Atheroscler Thromb, 14: 261-265. PMID: 17938541

Zhang, J.L. Ji, D. Fogt and V. Fretwell, 2007. Effect of exercise duration on postprandial hypertriglyceridemia in men with metabolic syndrome. Applied Physiol., 103: 1339-1345. DOI: 10.1152/japplphysiol.00181.2007 